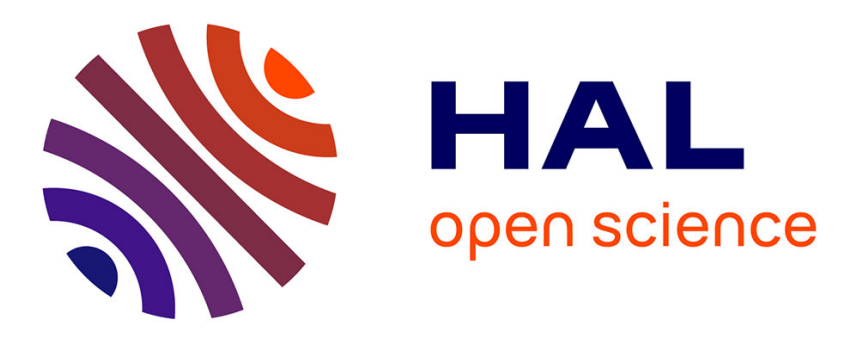

\title{
Determination of the Surface Temperature of Magnetically Heated Nanoparticles using a Catalytic Approach
}

Zarick Juliana Díaz-Puerto, Álvaro Raya-Barón, Piet W N M van Leeuwen, Juan M Asensio, Bruno Chaudret

\section{To cite this version:}

Zarick Juliana Díaz-Puerto, Álvaro Raya-Barón, Piet W N M van Leeuwen, Juan M Asensio, Bruno Chaudret. Determination of the Surface Temperature of Magnetically Heated Nanoparticles using a Catalytic Approach. Nanoscale, In press, 10.1039/D1NR02283K . hal-03275796

\author{
HAL Id: hal-03275796 \\ https://hal.science/hal-03275796
}

Submitted on 1 Jul 2021

HAL is a multi-disciplinary open access archive for the deposit and dissemination of scientific research documents, whether they are published or not. The documents may come from teaching and research institutions in France or abroad, or from public or private research centers.
L'archive ouverte pluridisciplinaire HAL, est destinée au dépôt et à la diffusion de documents scientifiques de niveau recherche, publiés ou non, émanant des établissements d'enseignement et de recherche français ou étrangers, des laboratoires publics ou privés. 


\title{
Determination of the Surface Temperature of Magnetically Heated Nanoparticles using a Catalytic Approach
}

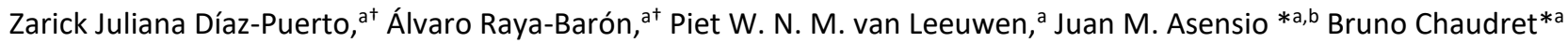

a. LPCNO, Université de Toulouse, INSA, CNRS, UPS, 31077 Toulouse, France. E-mail: chaudret@insa-toulouse.fr

b. Current address: IFP Energies nouvelles, Rond-point de l'échangeur de Solaize, BP 3, 69360 Solaize, France.

$\dagger$ Both authors contributed equally to this work.

\begin{abstract}
Herein we describe a new method for the determination of the surface temperature of magnetically heated nanoparticles in solution using the temperature dependency of the catalytic performances of iron carbide nanoparticles coated with ruthenium ( $\mathrm{Fe}_{2.2} \mathrm{C} @ \mathrm{Ru}$ ) for acetophenone hydrodeoxygenation. A correlation between nanoparticle surface temperature and magnetic field could be established. Very high surface temperatures could be estimated in different solvents, which were also found similar at a given magnetic field and well above some solvent boiling points.
\end{abstract}

Magnetic heating is a topic of interest that has been applied in medicine ${ }^{1}$ and more recently in catalysis, ${ }^{2}$ for activating both classical heterogeneous gas-phase reactions $s^{3,4,5,6,7,8,9}$ and catalysis in solution. ${ }^{10,11,12}$ The conceptual approach relies on the fact that, in the presence of an alternating magnetic field, ferromagnetic nanoparticles (NPs) release heat to the environment due to hysteresis losses. This technique presents several advantages such as the quasi-instantaneous heating of the catalyst, or the possibility of heating the reactor from the inside, which minimizes the heat losses and may have strong benefits for the energy efficiency of the technique. The heating power of magnetic NPs is usually quantified in units of $\mathrm{W} \cdot \mathrm{g}^{-1}$ by the so-called Specific Absorption Rate (SAR). This parameter, however, only provides information at a macroscopic scale, while the temperature at the surface of the nanoparticles and their immediate surroundings remain challenging to determine. A few studies have been devoted to the determination of the actual surface temperature of magnetic NPs in liquid phase by different strategies such as ligand degradation ${ }^{11,13,14,15}$ or fluorescence of inorganic materials. ${ }^{16,17}$ In some of these studies, it has been proposed that, upon magnetic excitation, there is generation of "local high temperatures" in the vicinity of the NPs, which behave as "hot spots" in a "cold environment" ${ }^{13}$ However, these and other ${ }^{18}$ methodologies all have in common their focus on medical applications (such as targeted drug delivery or induced cellular apoptosis) and therefore describe hyperthermia events in biological environments in which the rise of temperature remains limited near the physiological temperature and therefore does not exceed nor closely approaches the boiling point of an aqueous medium.

In the field of catalysis, the use of magnetic induction should allow us to reach temperatures much higher than those found in biological systems. Although the surface temperatures in those conditions remain unknown, there is experimental evidence of the presence of "hot-spots". Indeed, in previous works, ${ }^{10,19}$ we have shown that the hydrodeoxygenation (HDO) of furfural or 2-hydroxymethylfurfural, a reaction typically carried out at high temperature $\left(150-220^{\circ} \mathrm{C}\right)$ and pressure $(10-$ 50 bar) in heterogeneous catalysis, ${ }^{20}$ can be performed under apparently mild reaction conditions ( 3 bar of $\mathrm{H}_{2}$ ) and low catalyst loadings in mesitylene solution when catalyzed by $\mathrm{Fe}_{2.2} \mathrm{C} @ \mathrm{Ru}$ or by iron-nickel NPs enriched with $\mathrm{Ni}$ (FeNi ${ }_{3} @ \mathrm{Ni}$ ) using magnetic induction. ${ }^{10,19}$ The intense local reflux that was observed in the surrounding of the NPs, as well as the catalytic results, suggested that the reaction occurred at a temperature well above the boiling point of the solvent (mesitylene, b.p 165 ㅇ) . In this case, the methods applied in biological systems are likely to be inoperative, since the stability of the organic ligands or of the inorganic complexes might be compromised in such harsh conditions. Synchrotron techniques based upon lattice parameters modifications have been used by some of us to access to the internal temperature of magnetically-heated supported NPs. ${ }^{21}$ However, the method is complex and not representative of the behavior of the particles in solution. ${ }^{22}$ There is therefore a need for an easily-accessible technique to estimate the surface temperature of magnetic NPs under relevant catalytic conditions, for it would give insight on the feasibility of a process of interest.

In this work, we have used a kinetic approach for the estimation of the temperature at the surface of magnetic NPs in magnetically induced catalysis in solution, for which the HDO of acetophenone catalysed by $\mathrm{Fe}_{2.2} \mathrm{C} @ \mathrm{Ru}$ NPs was chosen as model reaction. These nanoparticles show a mean size of $13.6 \pm$ $1.6 \mathrm{~nm}$ (Figure S2 and S3) and consist in a $\mathrm{Fe}_{2.2} \mathrm{C}$ core decorated with smaller Ru NPs, and have been previously described and fully characterized by our group, therefore their magnetic and catalytic behaviours are well known. ${ }^{10}$ Such a system presents the advantage of having the catalytic species ( $\mathrm{Ru}$ ) directly attached to the heating agent $\left(\mathrm{Fe}_{2.2} \mathrm{C}\right)$, so that the temperature calculated must be the one at the surface of the magnetic NPs. Thus, a correlation between temperature and conversion values was built via the Arrhenius equation, ${ }^{23}$ and was later employed to infer a surface temperature from the conversion values obtained under magnetic induction at different field amplitudes. This correlation indeed demonstrates the presence of very high surface temperatures at the surface of the nanoparticles in solution. The method we describe here benefits from its simplicity at both chemical and instrumental levels, and proves an immediate practical applicability.

In order to build a correlation between temperatures and conversion values using the Arrhenius equation, we performed the $\mathrm{HDO}$ of acetophenone under 3 bar of $\mathrm{H}_{2}$ using conventional heating between $200{ }^{\circ} \mathrm{C}$ and $240{ }^{\circ} \mathrm{C}$ (Table 1). Reactions were 
carried out in a double-walled Fisher-Porter bottle to minimize heat losses (see Figure S1). Hexadecane was used as solvent because of its high boiling point $\left(287^{\circ} \mathrm{C}\right)$. The inner vessel was heated within a 1-octadecene bath at the temperatures indicated in Table 1 . Due to heat losses, the highest temperature we were able to reach was $240{ }^{\circ} \mathrm{C}$. Taking profit of the magnetic properties of the NPs used as catalysts (see Supporting Information), they were directly stirred by the stirring plate, assuming the role of a stirring bar and enabling the homogenization of the temperature inside the reactor. It is important to note that in all cases, the $\mathrm{Fe}_{2.2} \mathrm{C} @ \mathrm{Ru}$ NPs were completely insoluble in the reaction medium and they were agglomerated at the bottom of the flask, which is relevant for the reproducibility of the reaction when using different batches of catalyst. Conversion values are summarized in Table 1 . In all cases, the reaction was fully selective and ethylbenzene was observed as the only reaction product. Furthermore, neither 1phenylethanol nor styrene was observed as reaction intermediates since, at high temperatures, deoxygenation of 1phenylethanol occurs faster than ketone hydrogenation 24 (Scheme S1).

We established experimentally the order of acetophenone in the HDO reaction to determine the rate equation for the calculation of the rate constants $(k)$, and therefore the order of acetophenone in the correlation via Arrhenius equation. Using the method of initial rates, a series of experiments at $200{ }^{\circ} \mathrm{C}$ with different concentrations of acetophenone (69, 137, 206 and $272 \mathrm{mmol} \cdot \mathrm{L}^{-1}$ ) were carried out (see Table S1). The results indicated an apparent zero reaction order with respect to the acetophenone at the concentration of $272 \mathrm{mmol} \cdot \mathrm{L}^{-1}$ employed in the temperature-conversion correlation, likely due to the saturation of active sites on the catalyst.

Table 1. HDO of acetophenone catalyzed by $\mathrm{Fe}_{2.2} \mathrm{C} @ \mathrm{Ru}$ NPs using conventional heating at different temperatures and in absence of a magnetic field. a)

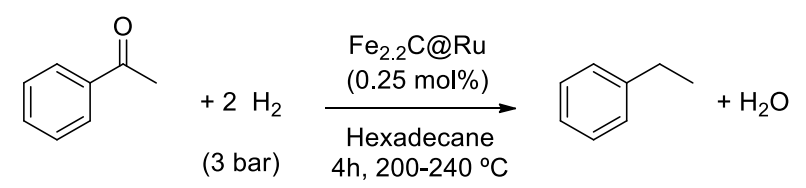

\begin{tabular}{ccc}
\hline Entry & Temperature $\left[{ }^{\circ} \mathrm{C}\right]^{\mathrm{b})}$ & Conversion $[\%]^{\mathrm{c})}$ \\
\hline 1 & 200 & 8 \\
2 & 210 & 11 \\
3 & 220 & 14 \\
4 & 230 & 19 \\
5 & 240 & 24 \\
\hline
\end{tabular}

a) Reaction conditions: Acetophenone (1.36 mmol), $\mathrm{H}_{2}$ (3 bar), FeC@Ru (5 mg, 0.25 mol\% Ru), hexadecane $(5 \mathrm{~mL})$, internal GC standard: dodecane $(1.29 \mathrm{mmol})$; b) Temperature measured in the external bath of 1-octadecene; c) Conversions determined by GC-MS.

From the data presented in Table 1 , combination of the integrated kinetic equation for a zero order reaction and Arrhenius equation allowed us to correlate $k$ with the different temperatures. The plot of $\ln k$ against $1 / T$ is shown in Figure 1.
Using the same batch of $\mathrm{Fe}_{2.2} \mathrm{C} @ \mathrm{Ru}$ NPs as both heating agent and catalyst, magnetically induced HDO of acetophenone was carried out under the same conditions ( 3 bar of $\mathrm{H}_{2}, 0.25 \mathrm{~mol} \%$ of $\mathrm{Ru}$ ) previously reported by some of us. ${ }^{10}$ Different field amplitudes at a fixed frequency of $300 \mathrm{kHz}$ were applied to the reaction, in order to correlate them to the apparent temperatures at the surface of the nanoparticles ( $\left.T_{\text {surf }}\right)$ calculated by the Arrhenius plot (Table 2 and Figure 2).

The methodology we have used to estimate the $\mathrm{T}_{\text {surf }}$ is somehow similar to the strategy followed by Riedinger et al. ${ }^{13}$ However, our approach presents the advantage of the utilization of a simple molecule that is presumably directly attached to the surface of the NPs. Interestingly, $\mathrm{T}_{\text {surf }}$ progressively increases upon increasing the $\mu_{0} H_{r m s}$, until reaching a maximum value of $260 \stackrel{\circ}{ } \mathrm{C}$ at $60 \mathrm{mT}$ but when the magnetic field amplitude rises to $65 \mathrm{mT}$, the $T_{\text {surf }}$ decreases. Since the mean temperature of the solution ( $T_{\text {mean }}$ ) increased linearly in all the range of $\mu_{0} H_{r m s}$ (Figure S4), we ascribed this decrease of $\mathrm{T}_{\text {surf }}$ to a loss of catalytic

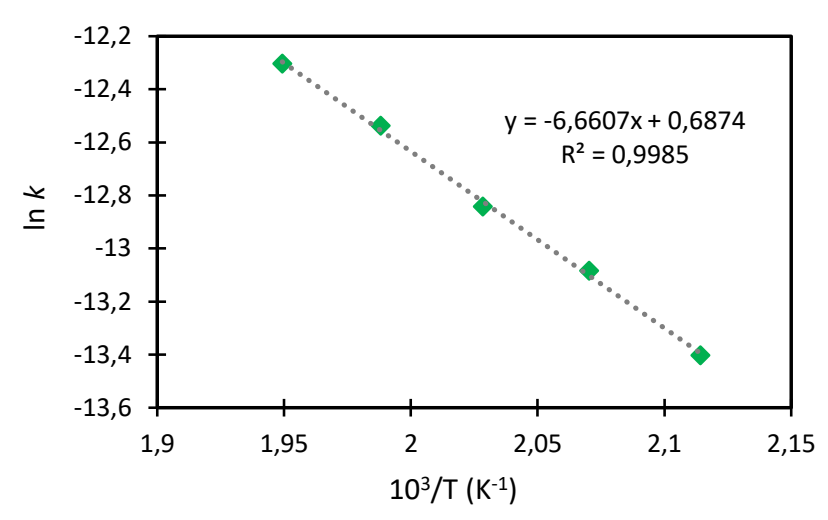

Figure 1. Arrhenius plot of HDO of acetophenone using conventional heating.

Table 2. HDO of acetophenone catalyzed by Fe2.2C@Ru NPs using magnetic induction at different field amplitudes.a)

\begin{tabular}{|c|c|c|c|}
\hline & $\begin{array}{l}+2 \mathrm{H}_{2} \\
\text { (3 bar) }\end{array}$ & $\begin{array}{c}\mathrm{Fe}_{2.2} \mathrm{C} @ \mathrm{Ru} \\
\underset{\text { Hexadecane }}{\stackrel{(0.25 \mathrm{~mol} \%)}{\longrightarrow}}\end{array}$ & $+\mathrm{H}_{3}$ \\
\hline Entry & $\begin{array}{c}\text { Magnetic field } \\
{[\mathrm{mT}]}\end{array}$ & $\begin{array}{c}\text { Conversion } \\
{[\%]^{\text {b) }}} \\
\end{array}$ & $\begin{array}{c}\text { Surface temperature } \\
{\left[{ }^{\circ} \mathrm{C}\right]}\end{array}$ \\
\hline 1 & 24 & 2 & 157 \\
\hline 2 & 33 & 10 & 207 \\
\hline 3 & 44 & 22 & 236 \\
\hline 4 & 53 & 32 & 251 \\
\hline 5 & 60 & 37 & 257 \\
\hline 6 & 65 & 25 & 241 \\
\hline
\end{tabular}

a) Reaction conditions: Acetophenone (1.36 mmol), $\mathrm{H}_{2}$ (3 bar), FeC@Ru (5 mg, 0.25 mol\% Ru), hexadecane $(5 \mathrm{~mL})$, internal GC standard: dodecane $(1.29 \mathrm{mmol})$; ${ }^{\text {b) }}$ Conversions determined by GC-MS.

activity caused by a higher degree of agglomeration or coalescence of the nanoparticles, as TEM (Figure 3) and STEMEDX (Figures S5 and S6) images show. The degree of agglomeration observed after the reaction at $65 \mathrm{mT}$ (Figure 3c) is much higher than that observed after a reaction with 
conventional heating (Figure 3b) or under magnetic induction at a lower field (Figure S7), both of which appear degraded but only slightly agglomerated. Furthermore, remains evenly distributed on iron carbide NPS. Such agglomeration of the FeC@Ru NPs would hamper their catalytic activity. In addition, the oxidation of the materials after catalysis was evidenced by XRD analysis (Figure S8). Alternatively, a shift in the ketone/alcohol equilibrium due to the high temperature is another possible cause of this decrease of the $T_{\text {surf }}$. However, we would like to note that, in the presence of an alternating magnetic field, the NPs organize into chains, so $\mathrm{T}_{\text {surf }}$ represent the mean temperature at the micrometric scale of several chains. We have previously observed that arrangement into chains is a requisite for NPs to display catalytic activity under magnetic induction, since it enhances their heating power and reduces the surface/volume ratio, slowing down the heat exchange to the environment. ${ }^{10}$

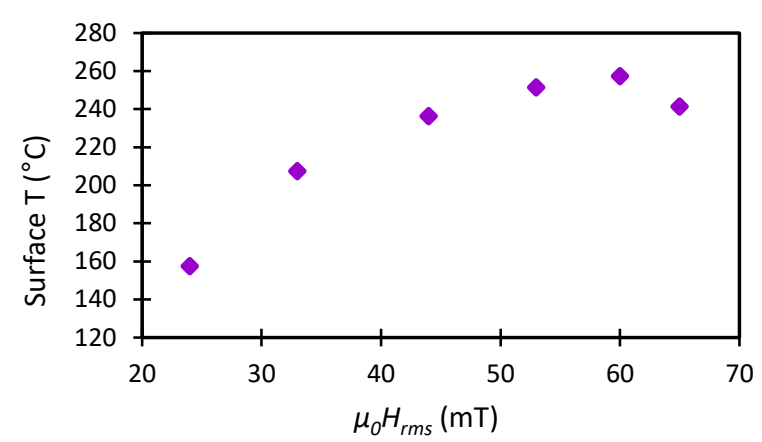

Figure 2. Correlation between the $\mathrm{T}_{\text {surf }}$ and the magnetic field amplitude, $\mu_{0} H_{r m s}(\mathrm{mT})$, at a $f$ of $300 \mathrm{kHz}$.

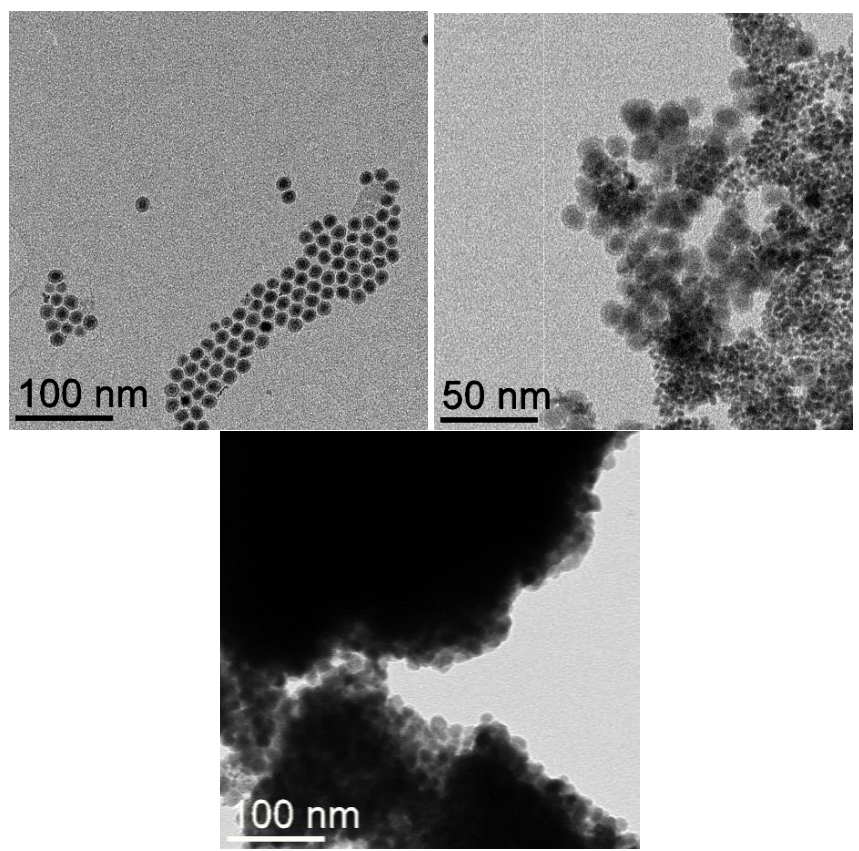

Figure 3. TEM images of $\mathrm{Fe}_{2.2} \mathrm{C} @$ Ru NPs. (a) Before being used in catalysis. (b) After use in catalysis under conventional heating at $220^{\circ} \mathrm{C}$ for $4 \mathrm{~h}$. (c) After use in catalysis under magnetic induction at $65 \mathrm{mT}$ for $4 \mathrm{~h}$.

The $\mathrm{T}_{\text {surf }}$ enables us to estimate the minimum temperatures that should be used by conventional heating to reach the desired conversion, so presumably this value has strong implications with the energy efficiency of the technique.

In previous experiments, ${ }^{10}$ we have observed that performing $\mathrm{HDO}$ of acetophenone in a mesitylene solution under magnetic induction leads to intense bubbling in the surroundings of the NPs. Thus, the temperature must be well above the boiling point of the solvent in order to explain the good catalytic activities. Aiming at understanding the effect of the boiling point of the solvent $\left(T_{b}\right)$, we performed the HDO of acetophenone using different solvents: toluene $\left(T_{b} 111{ }^{\circ} \mathrm{C}\right)$, mesitylene $\left(T_{b} 165{ }^{\circ} \mathrm{C}\right)$, dodecane $\left(T_{b} 219{ }^{\circ} \mathrm{C}\right)$ and hexadecane $\left(\mathrm{T}_{\mathrm{b}} 287^{\circ} \mathrm{C}\right)$, under otherwise identical reaction conditions, giving rise to the highest $\mathrm{T}_{\text {surf }}$ in dodecane $\left(60 \mathrm{mT}\right.$ field, 3 bar $\mathrm{H}_{2}, 0.25$ mol\% Ru loading). Since we have found the catalytic reactions to be reproducible, we assume that the surface-active area is comparable in all the different runs. The results are summarized in Table 3. We observed that upon decreasing the $T_{b}$ of the solvent, the pressure increased progressively inside the FisherPorter bottle due to the intensity of reflux. The highest pressure increase took place in the lowest boiling point solvent, toluene, though it was of only of 0.6 bar. For hexadecane, no solvent boiling was observed as it displays a $T_{b}$ above the $T_{\text {surf. }}$. The mean temperature $\left(T_{\text {mean }}\right)$ measured with an IR camera pointing at the reactor wall was in all cases below the $T_{b}$. Interestingly, despite the large differences in the $T_{\text {mean }}$ for the four experiments, the $\mathrm{T}_{\text {surf }}$ values were within the same range $(230-260 \stackrel{\circ}{\circ})$. It therefore demonstrates the possibility for catalysts magnetically heated to reach temperatures much higher than the boiling point of the solvent and therefore to carry out high temperature reactions in apparently mild operation conditions. We must point out that our estimation of the $T_{\text {surf }}$ on the surface of the NPs is solely based on the conversions obtained from the catalvtic HDO of acetophenone as herein described, this $m$ ( ${ }^{\text {(a) }}$ ng that should there be far (b) ; other than temperature affecting the conversion afforded by the process, the $T_{\text {surf }}$ estimated would stray further from the real value. We must also stress that this $\mathrm{T}_{\text {surf }}$ is an underestimation of the real temperature at the surface of the NPs since, for example, the formation of bubbles would prevent the substrate from approaching the "hot" metal center and hence lead to an apparent lower surface temperature. In any case, this method gives an estimation of the surface temperature which happens to grow as the difference between the real surface temperature and the boiling point of the solvent increases. In this respect, the temperature measured in hexadecane $\left(257^{\circ} \mathrm{C}\right)$ can be used as the real surface temperature. The very low difference observed between the temperature in dodecane and hexadecane presumably results from the experimental error. It is remarkable that a very similar surface temperature $\left(251^{\circ} \mathrm{C}\right)$ is estimated in mesitylene, the boiling point of which is only $165^{\circ} \mathrm{C}$. 
Table 3. Apparent surface temperature for acetophenone HDO under magnetic heating (60 mT field) in different solvents. ${ }^{\text {a) }}$

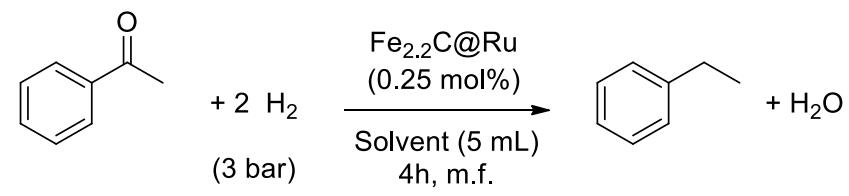

\begin{tabular}{ccccccc}
\hline Entry & Solvent & $\begin{array}{c}\mathrm{T}_{\mathrm{b}} \\
\left({ }^{\circ} \mathrm{C}\right)\end{array}$ & $\begin{array}{c}\Delta \mathrm{P} \\
(\mathrm{bar})\end{array}$ & $\begin{array}{c}\text { Conv. } \\
(\%)^{\mathrm{b})}\end{array}$ & $\begin{array}{c}\mathrm{T}_{\text {surf }} \\
\left({ }^{\circ} \mathrm{C}\right)\end{array}$ & $\begin{array}{c}\mathrm{T}_{\text {mean }} \\
\left({ }^{\circ} \mathrm{C}\right)\end{array}$ \\
\hline 1 & Toluene & 111 & 0.6 & 22 & 236 & 105 \\
2 & Mesitylene & 165 & 0.2 & 32 & 251 & 160 \\
$3^{\mathrm{c})}$ & Dodecane & 219 & 0.1 & 41 & 262 & 210 \\
4 & Hexadecane & 287 & $<0.1$ & 37 & 257 & 250
\end{tabular}

a) Reaction conditions unless otherwise noted: Acetophenone (1.36 mmol), $\mathrm{H}_{2}$ (3 bar), FeC@Ru (5 mg, $0.25 \mathrm{~mol} \% \mathrm{Ru})$, solvent (5 mL), internal GC standard: dodecane $(1.29 \mathrm{mmol})$, magnetic induction heating by a field of $60 \mathrm{mT}$; b) Conversions determined by GC-MS. c) Internal GC standard: decane (1.36 mmol).

\section{Conclusions}

To conclude, in this work we have estimated the temperature ( $\left.T_{\text {surf }}\right)$ at the surface of $\mathrm{Fe}_{2.2} \mathrm{C} @ \mathrm{Ru}$ NPs in magnetically induced HDO of acetophenone carried out in hexadecane solution. We have observed that, as expected, the different $\mathrm{T}_{\text {surf }}$ are dependent upon the magnetic field amplitude, reaching a maximum value of $260 \stackrel{\circ}{ } \mathrm{C}$ at $60 \mathrm{mT}$. Furthermore, we demonstrate for the first time that, even when reducing the $T_{b}$ of the solvent from 287 to $110^{\circ} \mathrm{C}$, the $\mathrm{T}_{\text {surf }}$ on the NPs remains of the same order of magnitude $\left(230-260^{\circ} \mathrm{C}\right)$. This observation evidences the presence in solution of local high-temperatures that can be well above the boiling point of the solvent, and well above the mean temperature of the solution. It explains the excellent catalytic performances of this system for HDO of acetophenone and other aromatic ketones in toluene or mesitylene.

\section{Conflicts of interest}

There are no conflicts to declare.

\section{Acknowledgements}

The authors thank ERC Advanced Grant (MONACAT 2015-694159) for financial support. The authors also thank Simon Cayez for recording the STEM-EDX images.

\section{Text for TOC}

The surface temperature on catalytically active magnetic nanoparticles ( $\left.\mathrm{Fe}_{2.2} \mathrm{C} @ \mathrm{Ru}\right)$ was estimated from their catalytic performances for the hydrodeoxygenation of acetophenone under magnetic induction. In different solvents surface temperatures well-above above the boiling point of the solvents used were determined.

\section{References}

1 V. F. Cardoso, A. Francesko, C. Ribeiro, M. Bañobre-López, S. Lanceros-Mendez, Adv. Healthcare Mater., 2018, 7, 1700845.

2 W. Wang, G. Tuci, C. Duong-Viet, Y. Liu, A. Rossin, L. Luconi, J.-M. Nhut, L. Nguyen-Dinh, C. Pham-Huu, G. Giambastiani, ACS Catalysis, 2019, 9, 7921.

3 A. Bordet, L-M. Lacroix, P.-F. Fazzini, J. Carrey, K. Soulantica, B. Chaudret, Angew. Chem. Int. Ed., 2016, 55, 15894.

4 A. Meffre, B. Mehdaoui, V. Connord, J. Carrey, P. F. Fazzini, S. Lachaize, M. Respaud, B. Chaudret, Nano Lett., 2015, 15 3241.

5 A. Meffre, B. Mehdaoui, V. Kelsen, P. F. Fazzini, J. Carrey, S. Lachaize, M. Respaud, B. Chaudret, Nano Lett., 2012, 12 4722.

6 S. S. Kale, J. M. Asensio, M. Estrader, M. Werner, A. Bordet, D. Yi, J. Marbaix, P.-F. Fazzini, K. Soulantica, B. Chaudret, Catal. Sci. Technol., 2019, 9, 2601.

7 M. G. Vinum, M. R. Almind,. J. S. Engbaek, S. B. Vendelbo, M. F. Hansen, C. Frandsen, J. Bendix, P. M. Mortensen, Angew. Chem. Int. Ed., 2018, 57, 10569.

8 F. Varsano, M. Bellusci, A. La Barbera, M. Petrecca, M. Albino, C. Sangregorio, Int. J. Hydrogen Energy, 2019, 44 21037.

9 W. Wang, C. Duong-Viet, Z. Xu, H. Ba, G. Tuci, G. Giambastiani, Y. Liu, T. Truong-Huu, J.-M. Nhut, C. PhamHuu, Catal. Today, 2020, 357, 214.

10 J. M. Asensio, A. B. Miguel, P.-F. Fazzini, P. W. N. M. van Leeuwen, B. Chaudret, Angew. Chem. Int. Ed., 2019, 58 , 11306

11 T. T. T. N'Guyen, H. T. T. Duong, J. Basuki, V. Montembault, S. Pascual, C. Guibert, J. Fresnais, C. Boyer, M. R. Whittaker, T. P. Davis, L. Fontaine, Angew. Chem. Int. Ed., 2013, 52, 14152.

12 J. Hartwig, S. Ceylan, L. Kupracz, L. Coutable, A. Kirschning, Angew. Chem. Int. Ed., 2013, 52, 9813.

13 A. Riedinger, P. Guardia, A. Curcio, M. A. Garcia, R. Cingolani, L. Manna, T. Pellegrino, Nano Lett., 2013, 13, 2399.

14 N. Griffete, J. Fresnais, A. Espinosa, C. Wilhelm, A. Bee, C. Menager, Nanoscale, 2015, 7, 18891.

15 J. T. Dias, M. Moros, P. del Pino, S. Rivera, V. Grazu, J. M. de la Fuente, Angew. Chem. Int. Ed., 2013, 52, 11526.

16 R. Pinol, C. D. S. Brites, R. Bustamante, A. Martinez, N. J. O. Silva, J. L. Murillo, R. Cases, J. Carrey, C. Estepa, C. Sosa, F. Palacio, L. D. Carlos, A. Millán, ACS Nano, 2015, 9, 3134.

17 J. Dong, J. I. Zink, ACS Nano, 2014, 8, 5199.

18 E. Cazares-Cortes, S. Cabana, C. Boitard, E. Nehlig, N. Griffete, J. Fresnais, C. Wilhelm, A. Abou-Hassan, C. Ménager, Adv. Drug Deliv. Rev., 2019, 138, 233.

19 I. Mustieles Marin, D. De Masi, L.M. Lacroix, P.F. Fazzini, P.W.N.M. van Leeuwen, J.M. Asensio, B. Chaudret, Green Chem., 2021, 23, 2025.

20 L. Offner-Marko, A. Bordet, G. Moos, S. Tricard, S. Rengshausen, B. Chaudret, K.L. Luska, W. Leitner, Angew. Chem. Int. Ed., 2018, 57, 12721.

21 S. Faure, N. Mille, S. S. Kale, J. M. Asensio, J. Marbaix, P. Farger, D. Stoian, W. van Beek, P.-F. Fazzini, K. Soulantica, B. Chaudret, J. Carrey, J. Phys. Chem. C, 2020, 124, 22259

22 J.M. Asensio, J. Marbaix, N. Mille, L.M. Lacroix, K. Soulantica, P.F. Fazzini, J. Carrey, B. Chaudret, Nanoscale, 2019, 11, 5402

23 S. Arrhenius, Z. Physik. Chem., 1889, 4, 226.

24 L. Vilcocq, A. Cabiac, C. Especel, S. Lacombe, D. Duprez, J. Catal. 2014, 320, 16; B. Hocevar, M. Grilc, M. Hus, B. Likozar, Appl. Catal. B, 2017, 218, 147. 